\title{
Resenha - O fim das certezas - tempo, caos e as leis da natureza de Ilya Prigogine
}

\author{
Book Review - The end of certainty - time, chaos end the new laws of nature by Ilya Prigogine \\ Saulo Luis Lima da Silva*1@, Herman Fialho Fumiã ${ }^{2}$ \\ ${ }^{1}$ Centro Federal de Educação Tecnológica de Minas Gerais, Nepomuceno, MG, Brasil. \\ ${ }^{2}$ Pesquisador Autônomo, Divino, MG, Brasil.
}

\author{
Recebido em 13 de janeiro de 2022. Revisado em 24 de janeiro de 2022. Aceito em 25 de janeiro de 2022.
}

\begin{abstract}
Neste trabalho, apresentamos a resenha do livro O fim das certezas - tempo, caos e as leis da natureza de Ilya Prigogine, publicado em 1996. Prigogine é ganhador do prêmio Nobel de química de 1977 por suas contribuições ao estudo dos sistemas fora do equilíbrio. Não é exagero dizer que esse livro aborda suas principais conclusões sobre esse tema ao longo de um vida dedicada ao assunto. Embora o autor seja muito claro e didático, o tema é extremamente complexo. Alguns capítulos exigirão maior concentração e talvez uma (ou duas) releitura. O esforço é mais do que compensador. O autor nos levará pelas questões mais polêmicas e ainda em aberto na física. Ele não se acanha em discordar dos maiores pensadores da história e faz isso com sobriedade e argumentos sólidos. Podemos resumir a questão central da obra em: passado e futuro são distintos? Já adiantamos que a ingenuidade dessa questão é apenas aparente. A tentativa de responder essa questão faz com que o autor proponha mudanças radicais na visão de mundo apresentada pela física desde Newton. Tais mudanças incluem uma extensão da mecânica clássica e uma formulação unificada da mecânica quântica. Com essa resenha, esperamos auxiliar a leitura dos interessados nessa obra rica, profunda, prazerosa e empolgante.
\end{abstract}

Palavras-chave: Prigogine, Fim das certezas, Caos.

In this work, we present a book review of The end of certainties - time, chaos and the new laws of nature by Ilya Prigogine, published in 1996. For his contributions to the study of out-of-equilibrium systems, Prigogine was awarded the Nobel Prize in Chemistry in 1977. Without exaggeration, we can state that this book contains the main conclusions on the subject obtained throughout the author's life. The author's presentation of the subject is clear, yet the issue is quite complex. Some chapters will require extra attention and probably one (or two) re-readings. Regardless, the effort is worthwhile. The author leads us to the most controversial questions still open in physics. Prigogine is not afraid to disagree with history's greatest minds and does so with sobriety and solid arguments. Is there a difference between the past and the future? This is the core question of the work and it is certainly not a naive question. The author argues fundamental changes in the world view offered by physics since Newton in an attempt to answer this question. An extension of classical mechanics and a unified definition of quantum mechanics are among the changes. We hope this review helps those interested in reading this rich, deep, pleasurable, and exciting work.

Keywords: Prigogine, End of certainties, Chaos.

Neste trabalho, apresentamos a resenha do livro $O$ fim das certezas - tempo, caos e as leis da natureza de Ilya Prigogine, publicado originalmente em 1996 [1]. A tradução para o português utilizada foi a de Roberto Leal Ferreira, publicada pela editora Unesp [2]. Logo na abertura do livro, Prigogine explica que sua ideia original era apenas a tradução do livro entre o tempo e a eternidade, que fora escrito conjuntamente com Isabelle Stengers. No entanto, devido aos grandes avanços na área, Prigogine se viu forçado a proceder uma grande revisão na obra. Devido a isso, segundo ele, Isabelle Stengers prefiriu não aparecer mais como autora, mas apenas como uma colaboradora do "novo" livro.

\footnotetext{
*Endereço de correspondência: saulolimasilva@yahoo.com.br
}

Uma primeira advertência ao leitor interessado se faz necessária. Embora na orelha do livro o autor escreva que a obra está em uma forma "acessível a todos os leitores interessados na evolução das nossas ideias sobre a natureza", sem um prévio conhecimento de matemática, mecânica newtoniana, mecânica analítica, mecânica quântica, termodinâmica e física estatística o leitor não será capaz de apreender o essencial das discussões levantadas no livro. Nos agradecimentos de "uma breve história do tempo" Stephen Hawking diz que alguém lhe disse que cada equação matemática colocada no livro reduziria as vendas pela metade [3]. Aparentemente, Prigogine tinha pouco apego por retornos pecuniários.

Ao leitor menos familiarizado com as discussões mais fundamentais da física, a questão central do livro pode 
parecer ingênua e trivial. Podemos resumi-la da seguinte forma: passado e futuro são distintos? Já adiantamos que a ingenuidade dessa questão é apenas aparente. Todas as nossas experiências cotidianas nos levam a responder positivamente à questão. Já a física - ciência mais fundamental e de maior êxito em termos de precisão de medidas, previsão de resultados e avanços tecnológicos - responde negativamente (por mais inacreditável que isso possa parecer). Está interessado em saber mais sobre isso? Se sim, esse livro é para você!

Já nos agradecimentos somos apresentados ao objetivo do livro: transmitir ao leitor a convicção do autor de que estamos assistindo a uma mudança radical da direção seguida pela física desde Newton. Mas é no prólogo, no entanto, que o autor detalha melhor esse objetivo. A questão central a ser discutida é: a natureza (e suas leis) é determinista? O autor não esconde que sua visão é negativa em relação a essa questão. O prólogo é apresentado de forma bastante densa e com muita informação. Embora essa densidade nos deixe ansiosos pelos próximos capítulos, também nos deixa com a incerteza sobre se o autor será capaz de cumprir tudo o que promete. Em certa medida, podemos afirmar que o autor cumpre o prometido de forma honesta e lúcida. $\mathrm{O}$ livro apresenta as principais conclusões sobre o trabalho de uma vida do ganhador do prêmio Nobel de química de 1977 por suas contribuições à área através de seus estudos sobre sistemas fora do equilíbrio. Essa é uma leitura muito enriquecedora e prazerosa.

A grande densidade de informações é uma característica de todos os capítulos do livro. Essa característica pode deixar o leitor perdido no início. No entanto, a maioria das informações são repetidas inúmeras vezes ao longo da obra. É como se o autor apresentasse de uma só vez tudo que será abordado e em cada capítulo ele se aprofundasse em um desses tópicos, mas sem deixar de mencionar todas as outras informações a serem melhores examinadas nos capítulos seguintes. Gostando ou não dessa forma de apresentação, ter isso em mente ao começar a leitura é de grande ajuda para a compreensão da obra.

O capítulo 1, intitulado o Dilema de Epicuro, é o maior. Ele começa abordando o pensamento dos gregos antigos e termina na mecânica quântica. Esse é um daqueles capítulos em que, caso o leitor sinta-se perdido em meio a tantas informações, vale a pena insistir na leitura e após terminado o livro, refazer a leitura apenas desse capítulo. Podemos dizer que aqui será feito um panorama de tudo o que será discutido nas próximas páginas. Além disso, fica ainda mais nítida a complexidade do tema que o autor se propõe a abordar. Ele nos lembra que Epicuro introduz a ideia de clinamen para conciliar o livre-arbítrio e a possibilidade de mudanças com sua filosofia atomista ${ }^{1}$ Segundo o autor,

\footnotetext{
${ }_{1}$ Embora fuja do escopo da obra de Prigogine, uma leitura muito interessante e enriquecedora sobre as diferenças entre o atomismo de Demócrito e Epicuro pode ser encontrada na referência 4].
}

desde então o pensamento ocidental é assombrado pela seguinte questão: o destino está determinado, conforme sugere as leis da física, ou é incerto como afirma a história, filosofia, psicologia e praticamente todas as outras áreas do conhecimento? Entre os defensores da primeira opção estão físicos célebres como Newton, Leibniz, Laplace, Einstein, Weinberg e vários outros. Já entre os partidários da segunda opção o autor cita, entre outros, Heráclito, Hegel, Husserl, Bergson e Heidegger.

A argumentação seguinte é a de que o conceito de entropia, diferenciando processos reversíveis de irreversíveis, é interpretada pela maior parte dos físicos contemporâneos não como uma propriedade fundamental da natureza, mas como uma consequência do caráter aproximado, macroscópico, da descrição boltzmanniana. $\mathrm{O}$ autor reforça que o ponto de vista defendido pelo livro não é esse. Segundo ele:

- Os processos irreversíveis (associados à flecha do tempo) são tão reais quanto os processos reversíveis descritos pelas leis tradicionais da física; não podendo ser interpretados como aproximações das leis fundamentais;

- Os processos irreversíveis desempenham um papel construtivo na natureza;

- A irreversibilidade exige uma extensão da dinâmica.

Na mecânica, podemos estudar um sistema em termos de suas trajetórias ou da densidade dos pontos no espaço de fase através de uma distribuição de probabilidade. A questão central é: essas descrições são equivalentes? A resposta de muitos físicos célebres, como Einstein e Gibbs, é sim. Prigogine, no entanto, discorda. Ele acredita que a equivalência se dá apenas em sistemas estáveis. Por outro lado, um sistema instável:

"destrói a equivalência entre o nível individual e o nível estatístico e as probabilidades ganham um significado intrínseco, irredutível a uma interpretação em termos de ignorância ou de aproximação. (...) A descrição probabilista é mais rica do que a descrição individual. ( $\cdots$ ) As condições iniciais não podem mais ser assimiladas a um ponto no espaço das fases, elas correspondem a uma região descrita por uma distribuição de probabilidade. Trata-se, portanto, de uma descrição não-local. Além disso, a simetria em relação ao tempo é quebrada, pois, na formulação estatística, o passado e o futuro desempenham papéis diferentes." [2]

Os trabalhos de Poincaré sobre a integrabilidade dos sistemas é essencial nesse contexto.

"Um sistema dinâmico integrável é um sistema cujas variáveis podem ser definidas de tal maneira que a energia potencial seja eliminada, ou seja, de tal maneira que seu 
comportamento se torne isomorfo ao de um sistema de partículas livres, sem interação. Poincaré mostrou que, em geral, tais variáveis não podem ser obtidas. Com isso, em geral, os sistemas dinâmicos são não integráveis." 2

Além disso, Poincaré mostrou que a nãointegrabilidade do sistema se deve à existência de ressonâncias entre os graus de liberdade do sistema. Prigogine afirma que hoje nossa compreensão sobre a reversibilidade temporal na física está sendo renovada graças aos trabalhos iniciados por Kolmogorov e continuados por Arnold e Moser (conhecido como teoria KAM). O ramo da matemática conhecido com análise funcional seria a ferramenta necessária para obtermos a extensão necessária à dinâmica.

O capítulo 1 é finalizado com uma discussão sobre a mecânica quântica. É levantado aqui os grandes problemas ainda em aberto na mecânica quântica:

- Qual o papel da medida em um sistema quântico?

- Qual o limite entre o mundo regido pela física clássica e aquele regido pela física quântica?

Para o autor, todas as respostas dadas até o momento a essas questões são insatisfatórias. Ele defende que a situação é similar ao que vemos na mecânica clássica e as soluções também são similares. O problema, em ambos os casos, está na instabilidade. Embora na mecânica quântica não haja trajetórias, a instabilidade associada às ressonâncias de Poincaré conserva um sentido preciso tanto na mecânica quântica quanto na mecânica clássica. É nas interações que os termos difusivos se tornam dominantes. Prigogine está convencido de que estas questões nos levarão a uma formulação unificada da mecânica quântica e, o que é mais inesperado, a uma extensão da teoria clássica. Essa nova concepção precisa abandonar, na mecânica clássica, uma tradição secular: tratar os sistemas físicos através de suas trajetórias. Em uma comparação entre o clinamen de Epicuro (que abriu o capítulo) e a situação da física atual, Prigogine diz:" Nenhuma formulação das leis da física que não leve em conta o papel construtivo do tempo poderá satisfazer nossa necessidade de compreender a natureza."

Um mês antes de sua morte, Einstein perdeu seu amigo (também físico) de toda uma vida, Michele Besso. Em uma carta de condolências à família do amigo, em 21 de março de 1955, Einstein escreveu:

"agora ele partiu desse estranho mundo antes de mim. Isso não significa nada. Para nós, fisicos, a distinção entre passado, presente e futuro é apenas uma ilusão teimosamente persistente." [5]

O título do capítulo 2 é uma clara referência a essa frase de Einstein, embora Prigogine tenha acrescentado, de forma provocativa, uma interrogação ao título. O título do capítulo é: Apenas uma ilusão?. Nele, é apresentado brevemente sua trajetória no estudo dos sistemas fora do equilíbrio. Essa trajetória se confunde com a própria história dessa ciência, lembrando que o autor foi um dos pioneiros nesse ramo. De forma resumida e didática, somos apresentados aos principais resultados desses estudos bem como às principais expectativas de desenvolvimentos futuros.

No capítulo 3, intitulado das probabilidade à irreversibilidade, o intuito é convencer o leitor de que estudar um sistema levando em conta conjunto estatísticos e não trajetórias não corresponde a uma descrição aproximada. Mais do que isso, pretende também mostrar que a descrição em nível de conjuntos estatísticos leva a soluções que não podem ser expressas em termos de trajetórias. Ele argumenta que a equivalência entre o ponto de vista individual e o ponto de vista estatístico é rompido em um modelo de sistema dinâmico instável. Nessa tentativa, o autor nos conduz de forma clara e com uma didática inacreditável a compreender conceitos fundamentais da física estatística e da teoria do caos. Em sua demonstração, Prigogine, fará uso da aplicação de Bernoulli e do operador de Perron-Frobenius.

O capítulo 4, intitulado As leis do caos, pode ser entendido como um aprofundamento significativo do capítulo anterior. Este é um capítulo complexo e de leitura mais difícil, uma releitura pode ser interessante e até necessária. A leitura conjunta com um pequeno livro do autor com o mesmo nome desse capítulo também pode ser de grande ajuda $[6]^{2}$ Somos brindados mais uma vez com a didática e poder de concisão do autor. Em menos de uma página ele consegue explicar as bases de todo o formalismo de operadores da mecânica quântica, tema que ele retornará em maiores detalhes no capítulo 6. Ele introduz aqui uma ideia que será melhor discutida também no capítulo 6: o espaço de Hilbert não é suficiente para tratar todos os sistemas na mecânica quântica. Para estudarmos sistemas irreversíveis, precisamos de um espaço que incorpore as funções singulares, generalizadas. O espaço adequado a esses estudos, segundo Prigogine, é conhecido como espaços de Hilbert generalizados ou espaços de Gelfand.

A limitação da dinâmica newtoniana bem como sua extensão é discutida no capítulo 5, denominado para além das leis de Newton. Embora o autor seja claro e use uma linha de raciocínio linear, o tema é profundo e a abordagem utilizada faz jus a essa profundidade. Trata-se de um capítulo em que um conhecimento pormenorizado da mecânica analítica e da álgebra linear é bem-vindo. Sem esse conhecimento, muito do conteúdo fica incompreensível. No entanto, mesmo para quem não tem o ferramental necessário para entender todas as argumentações, a leitura desse capítulo é interessante e é possível entender a ideia básica.

\footnotetext{
$\overline{2}$ O título original do livro é Le leggi del caos e foi publicado em 1993, antes, portanto, da obra objeto desta resenha.
} 
O capítulo 6, intitulado uma nova formulação da teoria quântica, analisa as modificações que a quebra de simetria temporal impõe à mecânica quântica. Prigogine salienta que, embora a mecânica quântica tenha muitos pontos radicalmente diferentes da mecânica clássica, elas se assemelham na simetria temporal e no determinismo. A equação de Schrödinger, que rege a função de onda, possui simetria temporal e é determinista, da mesma forma que a equação de Newton. Somos apresentados a uma incrível discussão sobre os fundamentos matemáticos da mecânica quântica com uma concisão, clareza e didática espantosas. São raros os livros textos sobre o assunto que conseguem atingir esse objetivo.

O capítulo 7 apresenta várias ideias e conclusões apresentadas anteriormente. Sua principal novidade é a introdução ao que será discutido no capítulo seguinte: a cosmologia. O capítulo 8, o tempo precede a existência?, versa sobre a cosmologia, conforme adiantado no capítulo 7. O tom desse capítulo é diverso dos outros no sentido de que é mais especulativo, como o próprio autor adverte. A ideia aqui é argumentar que o tempo não teve início nem terá fim, embora nosso universo tenha tido (provavelmente) início e terá (provavelmente) fim. Antes de entrar no problema cosmológico, propriamente dito, o autor vai apresentar argumentos para nos convencer que a relatividade restrita pode ser perfeitamente adequada à sua ideia de quebra de simetria temporal. Logo depois, somos apresentados a discussões ainda em aberto sobre a cosmologia e as aplicações da relatividade geral de Einstein.

O capítulo final da obra, um caminho estreito, é um dos mais agradáveis de ler e também mais poético. Não é por acaso que veremos ser citados aqui, Einstein, Gödel, Dostoiévski, Borges, Shakespeare, entre vários outros grandes nomes. Além de uma bela discussão sobre os fundamentos da física, o autor resume o objetivo do livro. Diz que não é a proposição de uma teoria baseada no caos total, tão pouco a de leis deterministas para a natureza, seria mais algo como um "meio termo" entre as duas. Nas palavras de Prigogine:

"O acaso puro é tanto uma negação da realidade e da nossa exigência de compreender o mundo quanto o determinismo o é. O que procuramos construir é um caminho estreito entre essas duas concepções que levam igualmente à alienação, a de um mundo regido por leis que não deixam nenhum lugar para a novidade, e a de um mundo absurdo, onde nada pode ser previsto nem descrito em termos gerais. (...) As leis não governam o mundo, mas este tampouco é regido pelo acaso. As leis físicas correspondem a uma nova forma de inteligibilidade que as representações probabilistas irredutíveis exprimem. Elas estão associadas à instabilidade e, quer no nível microscópico, quer no macroscópico, descrevem os eventos enquanto possíveis, sem reduzi-los a consequências dedutíveis ou previsíveis de leis deterministas". 2

Por fim, ressaltamos que a obra possui uma leitura agradável e fluida. Além disso, muito rica em informações, abordando as principais questões fundamentais ainda não resolvidas da física. A didática de Prigogine é irretocável. No entanto, a leitura da obra sem uma sólida noção das principais áreas da física prejudicará muito a compreensão de vários dos temas abordados. Nesse sentido, embora a leitura da obra possa ser feita - e até de forma enriquecedora - por uma pessoa sem formação em física básica, não se pode dizer que é uma obra direcionada a todos os públicos. A quantidade de termos técnicos, gráficos e equações dificultará a absorção de vários temas abordados por parte daqueles leitores menos familiarizados com essa abordagem.

\section{Agradecimentos}

Os autores agradecem à Professora Angélica Sousa da Mata, do Departamento de Física da Universidade Federal de Lavras, pela rigorosa leitura do trabalho e valiosas sugestões.

\section{Referências}

[1] I. Prigogine, La fin des certitudes - Temps, chaos et les lois de la nature (Éditions Odile Jacob, Paris, 1996).

[2] I. Prigogine, O fim das certezas - Tempo, caos e as leis da natureza (Editora Unesp, São Paulo, 1996).

[3] S.W. Hawking, Uma breve história do tempo (Editora Rocco, Rio de Janeiro, 2000), 30 a ed.

[4] K. Marx, Diferença entre a filosofia da natureza de Demócrito e a de Epicuro (Editora Boitempo, São Paulo, 2018).

[5] A. Calaprice, Assim falou Einstein (Editora Civilização Brasileira, Rio de Janeiro, 1998).

[6] I. Prigogine, As leis do caos (Editora Unesp, São Paulo, 2002) 